\begin{tabular}{|l|l|l|l|l|}
$\begin{array}{l}\text { Journal of } \\
\text { Endocrinology }\end{array}$ & C-W Chang et al. & $\begin{array}{l}\text { Hypoxia and trophoblast } \\
\text { differentiation }\end{array}$ & $\mathbf{2 3 6 : 1}$ & R43-R56 \\
\hline
\end{tabular}

REVIEW

\title{
Trophoblast lineage specification, differentiation and their regulation by oxygen tension
}

\author{
Ching-Wen Chang1,2, Anna K Wakeland1,2 and Mana M Parast1,2 \\ 'Department of Pathology, University of California San Diego, La Jolla, California, USA \\ 2Sanford Consortium for Regenerative Medicine, University of California San Diego, La Jolla, California, USA
}

Correspondence should be addressed to M M Parast: mparast@ucsd.edu

\section{Abstract}

Development of the early embryo takes place under low oxygen tension. Under such conditions, the embryo implants and the trophectoderm, the outer layer of blastocyst, proliferate, forming the cytotrophoblastic shell, the early placenta. The cytotrophoblasts (CTBs) are the so-called epithelial 'stem cells' of the placenta, which, depending on the signals they receive, can differentiate into either extravillous trophoblast (EVT) or syncytiotrophoblast (STB). EVTs anchor the placenta to the uterine wall and remodel maternal spiral arterioles in order to provide ample blood supply to the growing fetus. STBs arise through CTB fusion, secrete hormones necessary for pregnancy maintenance and form a barrier across which nutrient and gas exchange can take place. The bulk of EVT differentiation occurs during the first trimester, before the onset of maternal arterial blood flow into the intervillous space of the placenta, and thus under low oxygen tension. These conditions affect numerous signaling pathways, including those acting through hypoxia-inducible factor, the nutrient sensor mTOR and the endoplasmic reticulum stress-induced unfolded protein response pathway. These pathways are known to be involved in placental development and disease, and specific components have even been identified as directly involved in lineage-specific trophoblast differentiation. Nevertheless, much controversy surrounds the role of hypoxia in trophoblast differentiation, particularly with EVT. This review summarizes previous studies on this topic, with the intent of integrating these results and synthesizing conclusions that resolve some of the controversy, but then also pointing to remaining areas, which require further investigation.

\section{Introduction: placental development begins under low oxygen tension}

Placenta is a unique organ that connects the fetus to the uterine wall, while providing essential support functions like nutrient uptake and oxygen exchange for the developing fetus throughout gestation (recently reviewed by James et al. 2012, Burton \& Jauniaux 2015). In human pregnancy, before maternal circulation to the placenta is fully established at the end of the first trimester, development of the placenta is initiated within a low oxygen environment (Patel et al. 2010). It is under these conditions where the trophectoderm, the outer layer of the blastocyst (early embryo), begins to grow and differentiate, forming the cytotrophoblastic shell (James et al. 2012). Following implantation, cytotrophoblast (CTB) precursor cells expand and further 
differentiate into syncytiotrophoblast (STB) in floating villi or extravillous trophoblast (EVT) in anchoring villi (James et al. 2012). Further development of the placenta includes vascularization of the floating villi, leading to the establishment of an exchange interface between the fetal and maternal circulations (James et al. 2012). Although oxygen tension affects multiple facets of placental development, including vascularization of the villous tree, this review will focus predominantly on its effects on trophoblast, the epithelial compartment of the placenta. In addition, while animal studies will be reviewed where pertinent, the bulk of the review will be focused on the role of oxygen tension in human trophoblast differentiation and placentation.

\section{Oxygen tension during early placentation}

Intact samples of early post-implantation human gestations are rare; one such specimen (approximate clinically determined gestational age of 30 days) is shown in Fig. 1, highlighting the proliferative cytotrophoblastic shell. A study of additional such samples, as part of the Boyd Collection, has shown that maternal arterial connections with the intervillous space of the placenta are blocked by aggregates of trophoblast, which essentially act as a plug to halt maternal blood flow to the early gestation placenta (Burton et al. 1999). This provides indirect evidence that the growth of the cytotrophoblastic shell, as seen in Fig. 1, occurs under low oxygen $\left(\mathrm{O}_{2}\right)$. However, the first direct evidence for the relatively hypoxic environment during early implantation appeared in 1992, when Rodesch and coworkers first measured the changes in oxygen tension within the intervillous space of placenta and, somewhat surprisingly, found it to be significantly lower than endometrial oxygen tension (Rodesch et al. 1992). This, along with a follow-up study, found that the intervillous oxygen tension rises steeply from $\sim 20 \mathrm{mmHg}$ (equivalent to $2-3 \% \mathrm{O}_{2}$ ) between 8 and 10 weeks of gestation to $>50 \mathrm{mmHg}\left(>6 \% \mathrm{O}_{2}\right)$ after 12 weeks (Jauniaux et al. 2000). These findings likely reflect the physiologic changes in maternal spiral arteries, secondary to remodeling by invasive EVT (described later) and the dissolution of the trophoblast aggregates/plugs, permitting greater maternal blood flow into the intervillous space, thereby rapidly increasing $\mathrm{O}_{2}$ levels at the end of first trimester (Fig. 2) (Patel et al. 2010, James et al. 2012).

Nevertheless, the placenta grows significantly during this period of relative hypoxia. Specifically, differentiation of EVT occurs most extensively in the first trimester, including the process of vascular remodeling, by which a subset of EVT replaces maternal endothelium in the spiral arterioles, transforming these into low-resistance, highcapacitance vessels, which are able to meet the needs of the rapidly growing fetus later in gestation (James et al. 2012, Fisher 2015).
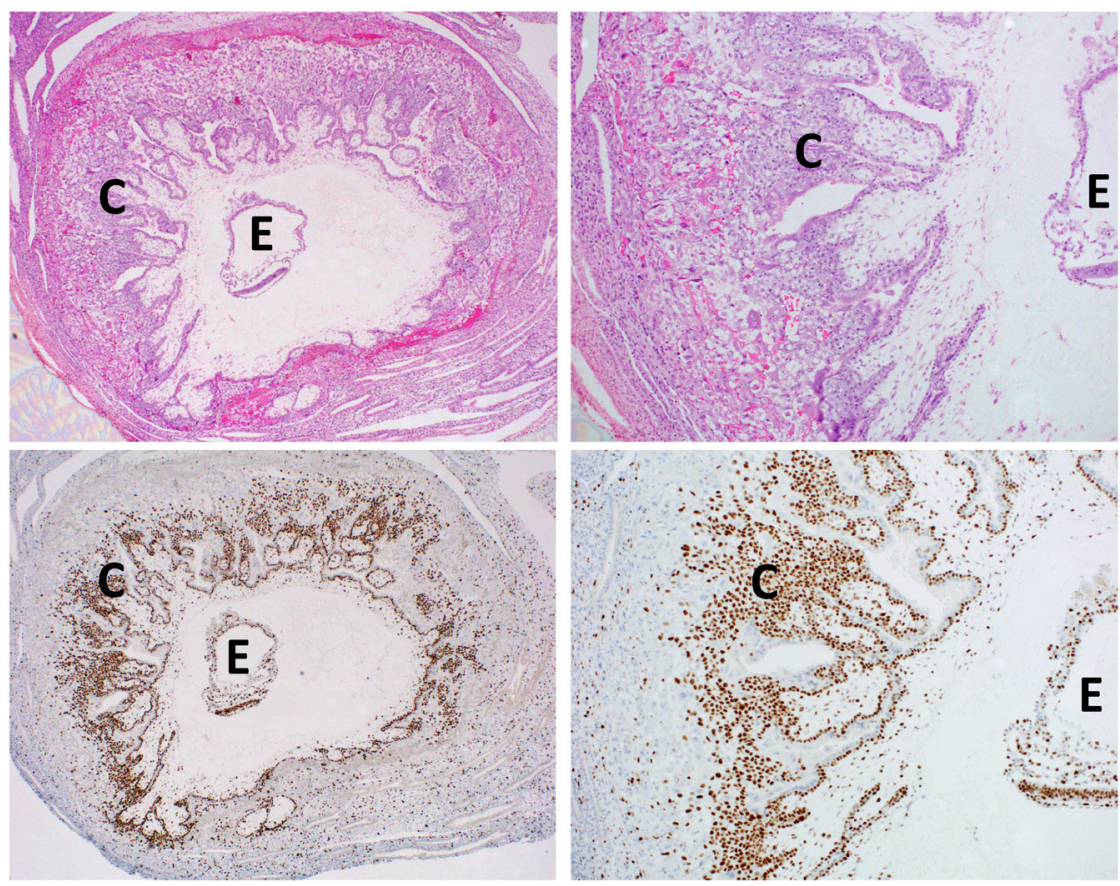

Figure 1

Early human embryo ( gestational age of 30 days), highlighting the proliferative cytotrophoblastic shell. $E=$ embryo, $\mathrm{C}=$ cytotrophoblastic shell. Top panels are H\&E stained, while bottom panels show Ki67 immunostaining. Magnification of 20x (left panels) or $50 \times$ (right panels). http://joe.endocrinology-journals.org https://doi.org/10.1530/JOE-17-0402 (c) 2018 Society for Endocrinology Published by Bioscientifica Ltd. Printed in Great Britain 


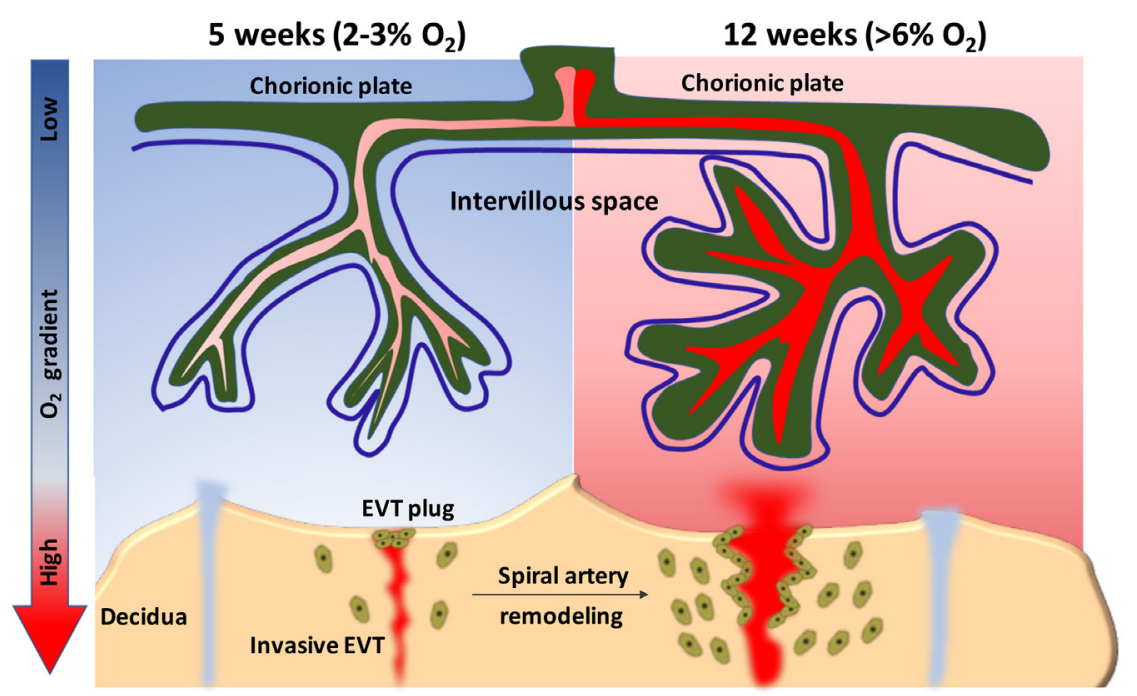

\section{Figure 2}

Schematic representation of the change of oxygen tension in human placenta from early to late first-trimester pregnancy. During this period, two types of extravillous trophoblasts with migratory and invasive capacities are found, including endovascular and interstitial trophoblasts. Endovascular trophoblasts invade into spiral arteries to form EVT plugs that prevent maternal blood flow into the intervillous space, thereby creating a low oxygen environment. Toward the end of the first trimester, these plugs gradually dissipate and endovascular trophoblasts begin migrating proximally along the vessel to cause spiral artery dilation, an important process for establishing the maternal-placental blood circulation, and therefore rapidly increasing the oxygen levels in support of fetal growth.

\section{Placental pathology associated with abnormal oxygenation}

The most common cause of placental dysfunction is the failure of vascular remodeling by EVT, also known as physiologic change, in maternal spiral arterioles, leading to such complications as miscarriage, early-onset severe preeclampsia (eo-sPE) and intrauterine growth restriction (IUGR) (Fisher 2015). While, in normal gestations, this physiologic change extends through the decidua and the superficial one-third of the myometrium, in PE, it is almost completely restricted to only the decidual segment of the spiral arteries (Brosens et al. 1972). It has therefore been concluded that in the absence of vascular remodeling by EVT, the spiral arteries cannot efficiently dilate, thereby restricting blood supply and oxygen delivery to the growing feto-placental unit.

Closer evaluation of such pregnancies, however, indicates that lack of physiologic change is more commonly associated with oxidative stress than with chronic hypoxia (Burton et al. 2009). In fact, lipid peroxidation and decreased activity of antioxidant enzymes, such as glutathione peroxidase and catalase, have been observed in PE (Poston \& Raijmakers et al. 2004). This is thought to be secondary to abnormal blood flow, which, in the absence of vascular remodeling, enters the intervillous space at a significantly faster rate, likely causing mechanical injury to the villous tree (Burton et al. 2009). This type of turbulent flow has been observed in ultrasound (Jauniaux et al. 1994) and has been associated with elevated levels of STB apoptosis. Second, nonremodeled spiral arteries retain their smooth muscle, making them more susceptible to vasoconstriction, and thus leading to hypoxia/reoxygenation (ischemic/ reperfusion) type of injury (Burton et al. 2009). Taken together, these data suggest that abnormal blood flow is the primary etiology of most disorders of placental function; nevertheless, dysfunctional blood flow also leads to abnormal activation of hypoxia-inducible pathways (see later), leading to the observed placental pathology. Thus, discussion of these pathways is relevant to placental development, in both normal and diseased gestations.

It should also be noted here that pregnancies at high altitude, which are by definition occurring under chronic hypoxia, are in fact associated with higher rates of PE and IUGR; however, abnormalities of spiral artery remodeling are not significantly increased in such pregnancies (Zamudio 2003). In fact, in normal gestations at high altitude, Doppler ultrasound studies reveal lower impedance to uterine artery blood flow, compared to normal gestations at sea level (Krampl et al. 2001). Instead, high-altitude placentas show a significant increase in fetal capillary density within chorionic villi, known as chorangiosis, which is considered to be an adaptive response to chronic hypoxia (Zamudio 2003, Julian 2011). Further studies are required to evaluate the relationship between various types of abnormal oxygen delivery and different patterns of adaptive response/injury in the placenta. Because this review is focused on the role of oxygen tension in trophoblast differentiation, there will not be further discussion of high-altitude pregnancies here. The reader is instead referred to other reviews on this subject (Zamudio 2003, Julian 2011). 


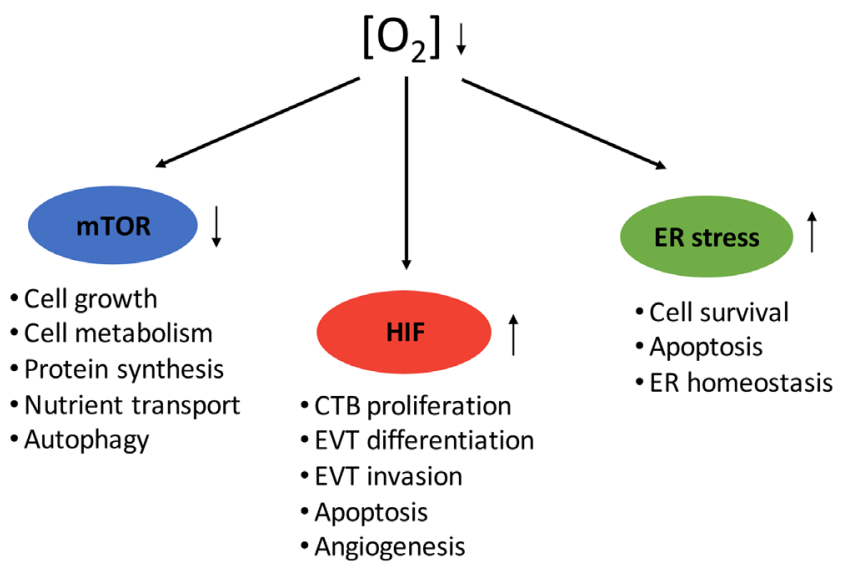

Figure 3

Three main pathways mediating effects downstream of low oxygen sensing in placenta and trophoblast.

\section{Pathways regulated by oxygen tension}

A low oxygen environment has been implicated as the crucial factor in the process of early embryonic and placental development in mammals (Kingdom \& Kaufmann 1997). Unlike other tissues, such as brain, which rapidly exhibit cellular damage under low oxygen conditions, the placenta is significantly more tolerant to such conditions (Kingdom \& Kaufmann 1997, Burton \& Jauniaux 2004, Simon \& Keith 2008). As summarized in Fig. 3, decreased oxygen tension leads to changes in cellular function through multiple oxygen-sensitive signaling pathways, including those downstream of hypoxiainducible factors (HIFs), mammalian target of rapamycin (mTOR) and the unfolded protein response (UPR) pathways. Activation of these pathways in trophoblast regulates gene expression, metabolic homeostasis and cell survival, among other processes (Busch et al. 2009, Patel et al. 2010, Burton \& Yung 2011). Defects in these pathways can, in turn, contribute to placental dysfunction and result in miscarriage, eo-sPE or IUGR. While there are numerous other pathways regulated by hypoxia, we will focus on these three (HIF, mTOR and UPR pathways) here, both for the sake of space and also because the bulk of the literature on hypoxia and placental development and disease is related to defects in these pathways.

\section{HIF-dependent mechanisms}

The classic oxygen-sensitive pathway through which the gene expression is regulated is HIF signaling. HIF is a heterodimeric transcription factor consisting of two subunits, HIF- $\alpha$ and HIF- $\beta$ (also termed ARNT, for aryl hydrocarbon receptor nuclear translocator) (Lee et al. 2004). Upon stabilization, HIF binds to specific promoter sequence elements via its N-terminal basic helix-loophelix domain, and then activates target gene transcription through its C-terminal transactivation domains and recruitment of coactivators such as $\mathrm{CBP} / \mathrm{p} 300$ to initiate transcription complex formation (Lee et al. 2004, Chen et al. 2009). To date, three HIF- $\alpha$ genes (HIF-1 $\alpha, H I F-2 \alpha$ and HIF-3 $\alpha$ ) have been identified in mammals; HIF-1 $\alpha$ is ubiquitously expressed, while expressions of HIF- $2 \alpha$ and HIF- $3 \alpha$ are more restricted to specific tissues (Lee et al. 2004); HIF-2 $\alpha$ mRNA and protein are both expressed in the placenta and trophoblast (Highet et al. 2015), while multiple HIF- $3 \alpha$ mRNA isoforms have been detected in the placenta, but have not been further evaluated in different compartments (Maynard et al. 2003). Unlike ARNT, which is constitutively expressed, HIF- $\alpha$ expression levels are tightly regulated by cellular oxygen concentration (Jewell et al. 2001). Under normoxic conditions, HIF- $\alpha$ protein undergoes rapid degradation following ubiquitylation by the von Hippel-Lindau tumor suppressor protein (pVHL), an E3 ubiquitin ligase; binding of pVHL to HIF- $\alpha$ requires hydroxylation of specific proline residues in HIF- $\alpha$ (Jaakkola et al. 2001). In addition to protein stability, the transcriptional activity of HIF can also be regulated. One such mechanism is through factor inhibiting HIF-1 (FIH-1), an Fe(II)-dependent enzyme, which utilizes molecular oxygen to modify its substrate (Lando et al. 2002). FIH-1 acts as an HIF suppressor to prevent the formation of transcription complex by inhibiting the interaction of $\mathrm{HIF}-1 \alpha$ with $\mathrm{CBP} / \mathrm{p} 300$. By contrast, under hypoxic conditions, both proline hydroxylation and binding to FIH-1 are blocked, resulting in protein stabilization and full activation of HIF transcription in the cell (Lando et al. 2002).

Studies using transgenic mouse models have shown a significant role for the intact HIF complex during placentation. Specifically, knockdown of Arnt and dual knockdown of Hif $1 \alpha / \mathrm{Hif} 2 \alpha$ both lead not only to defective vascularization of the placenta but also to aberrant trophoblast cell fate determination (Adelman et al. 2000, Cowden Dahl et al. 2005). In the absence of an intact HIF complex, the formation of spongiotrophoblast and trophoblast giant cells (TGCs), the equivalent to human EVT, is compromised. Instead, trophoblast stem cells (TSCs) differentiate exclusively into labyrinthine (villous) trophoblast (Adelman et al. 2000, Cowden Dahl et al. 2005, Maltepe et al. 2005). This switch in trophoblast lineage is mediated by changes in histone acetylation; in fact, the phenotype of Arnt-null TSC can be recapitulated 
in vitro by treating wild-type TSC with histone deacetylase inhibitors during differentiation (Maltepe et al. 2005).

In the human placenta, HIF- $1 \alpha$ protein expression is the highest in early (5-week gestational age) placental tissues (Caniggia et al. 2000). As pregnancy advances, HIF- $1 \alpha$ expression gradually decreases, becoming almost undetectable by the western blot around 12-week gestational age (Caniggia et al. 2000); this corresponds to the initiation of maternal blood flow into the intervillous space, which leads to an increase in physiological oxygen tension as mentioned previously. Interestingly, while HIF- $1 \alpha$ is expressed in both CTB and EVT in early gestation human placentas, we have also noted an increase in its expression during the transition from СТВ to proximal column EVT, both in vivo and in vitro (Wakeland et al. 2017). This is similar to mouse TSCs, which exhibit an increase in Hif $1 \alpha$ RNA levels during in vitro differentiation (Maltepe et al. 2005).

Once HIF $\alpha$ is stabilized, it complexes with HIF1 $\beta$ /ARNT and regulates transcription of numerous genes, including those involved in angiogenesis, glucose metabolism and cell survival (Lee et al. 2004). In preeclamptic placentae, shallow trophoblast invasion/incomplete vascular remodeling results in persistent hypoxia, leading in turn to continued HIF-1 $\alpha$ expression well into mid-tolate gestation (Rajakumar et al. 2004). This persistent expression of HIF- $1 \alpha$ is thought to at least contribute to the anti-angiogenic imbalance associated with preeclampsia, in particular to the rise in circulating levels of soluble VEGF receptor-1 (also known as soluble Fms-like tyrosine kinase-1 or sFlt-1) and soluble endoglin (sENG) (Tal 2012). sFlt-1, expressed primarily in STB and syncytial knots, was increased when human first-trimester villous explants were exposed either to low oxygen levels or to chemical inhibitors of prolyl-hydroxylases, which stabilize HIF- $1 \alpha$ (Nevo et al. 2006). Similarly, the sENG expression has also been shown to be induced under low oxygen conditions (Yinon et al. 2008). Further evidence of a role for HIF-1 $\alpha$ in pathogenesis of preeclampsia has come from rodent studies, where systematic administration of an adenovirus expressing a stabilized form of HIF-1 $\alpha$ to pregnant mice resulted in elevated blood pressure and proteinuria, reduced placental weights and fetal growth restriction, accompanied by elevated levels of serum sFlt- 1 and sEng (Tal et al. 2010).

\section{mTOR signaling pathway}

Another pathway affected by oxygen tension is mTOR. mTOR is a ubiquitously expressed serine/threonine kinase that integrates multiple environmental cues to regulate mRNA translation, cell growth and cell metabolism (Howell $\&$ Manning 2011). Two complexes exist, depending on the associated accessory protein: mTORC1 is associated with the accessory protein raptor, while mTORC2 complexes with the accessory protein rictor (Proud 2007, Howell \& Manning 2011); of these, mTORC1 has emerged as a major placental nutrient sensor over the past decade (Jansson et al. 2012). Upon stimulation by upstream factors like amino acids or growth factors, mTORC1 is activated and further phosphorylates its downstream targets, including eukaryotic initiation factor 4E-binding proteins (4E-BP1) and ribosomal S6 kinase-1 (S6K1), resulting in enhanced protein synthesis (Proud 2007). mTORC1 is highly expressed in the STB layer of the human placenta, where it has been shown to regulate the activity of amino acid transporters (Roos et al. 2007). Interestingly, the mTORC1 activity, as measured by levels of phosphorylated S6K1, has been found to be decreased in IUGR placentas, along with the activity of key placental amino acid transporters, suggesting that alterations in placental mTOR signaling are associated with adverse pregnancy outcomes (Roos et al. 2007). Finally, mice, deficient in either mTOR or raptor, die in the peri-implantation period, while those deficient in rictor die slightly later, around embryonic day 10.5 , suggesting potential abnormalities in early placental development (Gangloff et al. 2004, Murakami et al. 2004, Guertin et al. 2006).

Under low oxygen conditions, phosphorylation of mTOR and its effectors, including 4E-BP1 and S6K1, is reduced, an effect that is independent of the HIF complex (Arsham et al. 2003). This suggests that hypoxia likely initiates cellular energy conservation by inhibiting mTOR-mediated protein translation, thereby decreasing ATP consumption prior to oxygen becoming metabolically limiting. Notably, the mTORC1 signaling pathway also affects the transcription of genes involved in amino acid transport, lipid metabolism and immune modulation (Hudson et al. 2002). This might partly be mediated by increased translation of HIF- $1 \alpha$ in some cellular contexts. Finally, inactivation of mTOR signaling in human term STB, either by treatment with rapamycin or by culture in hypoxia, leads to induction of autophagy, a process by which the cell attempts to protect itself against apoptosis (Tuuli et al. 2011). While the exact mechanism(s) by which hypoxia regulates the mTOR pathway remain(s) unknown, mTOR likely plays a pivotal role in the integration of multiple signals, including low oxygen tension, and in synthesizing an appropriate response; thus, its continued study in the context of placental disorders, particularly IUGR, is imperative. 


\section{ER stress-mediated UPR pathway}

Another pathway-induced downstream of low oxygen tension is the endoplasmic reticulum (ER) stress-mediated UPR pathway. The ER is responsible for proper processing and folding of membrane-bound and secreted proteins; exposure to hypoxia, as well as other physiological or pathological stimuli, can disrupt the ER homeostasis, leading to an accumulation of misfolded or unfolded proteins and thus to 'ER stress' (Wouters et al. 2005, Guzel et al. 2017). To alleviate this stress and restore ER homeostasis, the UPR pathway is initiated, through detachment of the chaperone protein GRP78 from the three upstream transducers, ATF6, PERK and IRE1 (Wouters et al. 2005, Guzel et al. 2017). GRP78 is then free to bind the misfolded protein and induce UPR signaling; the result is proteasome-mediated degradation of unfolded/misfolded proteins, inhibition of translation initiation and restoration of ER homeostasis, or, in cases of severe or prolonged ER stress and cell death/ apoptosis (Wouters et al. 2005, Guzel et al. 2017). IRE1null mice exhibit placental abnormalities and die around embryonic day 12.5, indicating that the UPR pathway is required for proper placental development (Iwawaki et al. 2009). Additionally, transgenic mice with a mutation in the eukaryotic initiation factor 2 subunit alpha (eIF2 $\alpha$ ), which have an increased basal translation rate and thus increased ER stress, displayed premature differentiation of trophoblast progenitor cells, abnormal placentation, along with a reduction in placental and fetal weights (Yung et al. 2012). Furthermore, placentas from IUGR pregnancies, with and without preeclampsia, show evidence of increased ER stress (Yung et al. 2008). Finally, our own gene expression profiling data from human placental cells indicate that UPR is activated during the transition from CTB to proximal column EVT, thus indicating a potential role for this pathway during early placental development (Wakeland et al. 2017).

Overall, much remains to be probed regarding the role of the aforementioned pathways in placental development and disease, particularly with regard to the mTOR and UPR pathways. In addition, while the abovementioned pathways can be activated independently, growing evidence suggests that they act in an integrated manner, influencing each other in response to low oxygen tension during placental development. Therefore, future studies should employ systems' biology approaches, even when modulating one gene within one of these pathways, in order to optimally evaluate the role of these interdependent pathways during placental development.

\section{The controversy over 'hypoxic' conditions in vitro}

There has been considerable debate regarding the oxygen tension for optimal in vitro culture of trophoblast. It is generally accepted that for primary human trophoblast or placental explants, physiologic oxygen tension is $2-3 \%$ in the first trimester and 6-8\% in the second and third trimesters (Tuuli et al. 2011); hence, 'pathologic hypoxia' for such cells would be even lower oxygen tensions. A more difficult question arises with cell lines, including stem cell lines, which are often derived under room air, or $21 \%$ oxygen, for practical purposes. Unless these cells are first adapted to lower oxygen tensions over several passages, exposure of these cells to slightly lower oxygen tensions (8\%) may induce hypoxic responses, including HIF $\alpha$ stabilization (Tache et al. 2013). We therefore suggest testing at least three conditions with cell lines: $21 \%$ oxygen (as their adaptive environment), physiologic hypoxia (i.e. $8 \%$ if trying to mimic the environment of a term STB) and pathologic hypoxia (i.e. 1-2\%). Additional factors which must be considered when planning such experiments include culture media and duration of exposure to 'hypoxia'. Standard culture media often contain high levels of glucose, which, if not changed often, will result in increased oxidative stress (Tuuli et al. 2011). The duration of exposure to hypoxia should also be carefully considered, both in terms of the in vivo process(es), which the researcher is trying to mimic and with respect to the type of hypoxia chamber to use. For example, exposure to oxygen tensions below $1 \%$ for a prolonged period of time ( $>1$ day) can be toxic, causing irreversible damage, even to the hypoxia-tolerant trophoblast cells (Yang et al. 2016). While small hypoxic chambers (i.e. those that fit into a standard size incubator) are most common, large hypoxia incubators are significantly easier to use for prolonged culture under low oxygen levels. Our lab uses an XVIVO chamber (Biospherix, Parish, NY), which allows for maintenance, passage and monitoring of cells under continuous low oxygen conditions (Tache et al. 2013, Wakeland et al. 2017).

\section{Trophoblast differentiation and relevant model systems}

It is now clear that implantation and early placental development occur under low oxygen tension. During these events, the trophectoderm first undergoes rapid expansion (see Fig. 1) and also begins to differentiate into 
both villous (labyrinthine) trophoblast (including STB), involved in nutrient and gas exchange, and extravillous (junctional) trophoblast, involved in anchoring of the feto-placental unit to the uterine wall. Details of trophoblast differentiation can be found in recent reviews (James et al. 2012, John \& Hemberger 2012, Soncin et al. 2015).

How oxygen tension affects trophoblast proliferation and differentiation has been the subject of extensive research over the past $\sim 20$ years. For these studies, many different model systems have been used, including rodent models (both mouse and rat), human trophoblast cell lines and primary human villous explants and trophoblast. There are advantages and disadvantages of each of these models. Mice have been invaluable, both as transgenic animals for in vivo studies and because of the ability to derive TSCs from mouse embryos for in vitro work (Tanaka et al. 1998); however, there are significant differences between the mouse and the human placenta, particularly with respect to early embryonic development (Blakeley et al. 2015, Soncin et al. 2015). Rats offer the advantage of having significantly more invasive trophoblast, compared to mice, and thus have a maternal-fetal interface that more closely resembles that of humans (Soares et al. 2012). As in vitro human placental models go, villous explants provide structural context, with the distinct advantage of leaving intact the trophoblastic-mesenchymal interaction, thereby preserving, at least for a short period of time, CTB proliferation in vitro (Genbacev et al. 1997, Baczyk et al. 2006, Bilban et al. 2009). Primary isolated CTBs, particularly those from the term placenta, once separated from their underlying mesenchyme, tend to lose their proliferative capacity rather quickly, making the in vitro study of CTB self-renewal difficult at best. Human trophoblast cell lines have been used extensively, both to study CTB self-renewal and also to model both early gestation CTB and EVT, due to limited access to such tissues; however, these cells show significant differences in both gene expression and phenotype, when compared to primary CTB or EVT (Bilban et al. 2010); thus, caution should be used when conclusions are drawn from studies using only these cells. More recently, human pluripotent stem cells (hPSCs, including both embryonic stem cells and induced pluripotent stem cells) have been used by multiple groups to model both trophoblast lineage specification and further trophoblast differentiation, though not without controversy (recently reviewed by Li \& Parast 2014, Roberts et al. 2014); nevertheless, our studies have shown that hPSC-derived CTBs most closely resemble first-trimester CTBs, based both on genome-wide
RNA profiling and phenotype (Li et al. 2013, Horii et al. 2016). In the remainder of this review, we will discuss the role of hypoxia and hypoxia-regulated pathways, both in trophoblast lineage specification and in differentiation of the two main trophoblast lineages, STB and EVT, focusing mostly on studies using primary human cells and explants, but also mentioning rodent studies and hPSCbased models where relevant.

\section{Hypoxia and trophoblast lineage specification}

Little is known about trophoblast lineage specification in the human embryo (Chang \& Parast 2017), with most studies in this area using rodent models. Mice deficient in genes involved in hypoxia signaling, including the pathways discussed earlier, generally show defects either in the peri-implantation period (embryonic day 5.5-7.5) or around mid-gestation (embryonic day 10.5), suggesting problems in either maintenance of TSCs or later in trophoblast differentiation or chorioallantoic fusion, respectively. Trophoblast specification occurs during the transit of the embryo within the fallopian tube, where oxygen tension is low, albeit not as low as within the uterine cavity where implantation takes place (Fischer \& Bavister 1993). Although fertility clinics often culture human embryos under $5 \%$ oxygen, prior to embryo transfer, a recent study suggests that such conditions adversely affect the pluripotency of the cells within the inner cell mass (Shahbazi et al. 2016). hPSC, when previously adapted to low oxygen levels (4\%), showed a slower response to BMP4, delaying the induction of trophoblast lineage-specific markers (Das et al. 2007). However, our own studies of BMP4-treated hPSC did not note any significant differences in the onset of pluripotency (OCT4) loss or induction of TSC marker (CDX2 and p63), when BMP4 treatment was performed at either $21 \%$ or $5 \%$ oxygen tension (Fig. 4 ). Nevertheless, more studies are needed, including culture of embryos and hPSCs below 5\% oxygen, to more conclusively assess the optimal conditions for trophoblast lineage specification.

\section{Hypoxia and trophoblast differentiation}

\section{Hypoxia and STB differentiation}

STB is a layer of multinucleated cells, which forms and expands during pregnancy by cell-cell fusion of the underlying layer of mononuclear villous CTB. It is 


\section{OCT4}
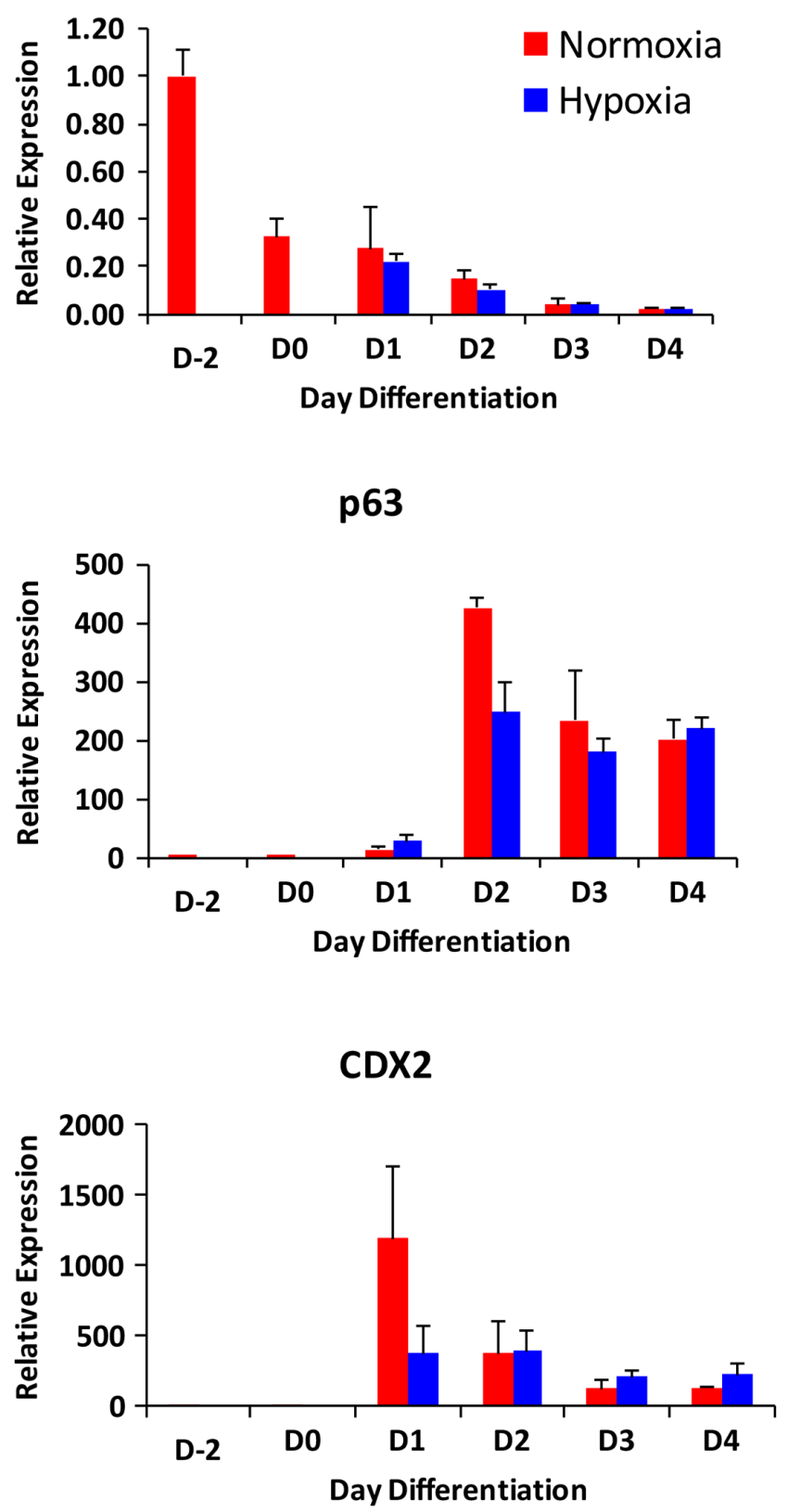

Figure 4

Trophoblast lineage specification is not affected in low oxygen tension. Human embryonic stem cell line (WA09/H9), adapted to StemPro (day 2), was switched to minimal media for 2 days (day 0 ), and then treated with $10 \mathrm{ng} / \mathrm{mL}$ BMP4 over a 4-day period (days 1-4, respectively) in either normoxia ( $20 \%$ oxygen) or hypoxia ( $5 \%$ oxygen) (for more experimental details, see Horii et al. (2016)). Cells were collected and RNA was isolated for quantitative PCR for the pluripotency marker, OCT4, as well as cytotrophoblast stem cell markers $p 63$ and CDX2. Values are normalized to $18 \mathrm{~S}$ rRNA, and shown as fold change relative to undifferentiated StemPro-adapted cells (day 2).

the main site for many placental functions such as gas exchange and nutrient transport, as well as secretory functions (i.e. of human chorionic gonadotropin/hCG and human placental lactogen/hPL) and critical hormones for pregnancy maintenance (Malassine \& Cronier 2002). CTBs isolated from various gestational age placentas spontaneously form multinucleated STBs by cell-cell fusion under atmospheric (21\%) oxygen. However, when oxygen levels are reduced, even only down to $10 \%$, this process is significantly impaired, with most CTBs remaining in a mononuclear state, and secreting significantly less of both hCG and hPL (Alsat et al. 1996). We have observed similar results when culturing first-trimester CTB or hPSC-derived CTB in $2 \% \mathrm{O}_{2}$, with both a decrease in cell-cell fusion and hCG secretion (Horii et al. 2016, Wakeland et al. 2017). We also found that this inhibition of STB differentiation was at least partly dependent on an intact HIF complex, as knockdown of HIF1 $\beta$ /ARNT in primary CTB partly restored hCG secretion (Wakeland et al. 2017).

STB formation is regulated through a master transcription factor, glial cells missing 1 (GCM1) and its downstream effector, SYNCYTIN-1, a fusogenic membrane protein (Baczyk et al. 2009, Wich et al. 2009). Compared to $21 \%$ oxygen, culture of primary-term CTB in 1\% oxygen led to a reduction in both GCM1 and SYNCYTIN-1, along with a reduction in cell-cell fusion (Wich et al. 2009). Downregulation of GCM1 by hypoxia has also been shown to be regulated by HIF in mouse TSCs: in the absence of Hif1ß/Arnt, mouse TSCs upregulate GCM1 and preferentially differentiate into multinucleated STBs (Maltepe et al. 2005). This reduction in GCM1 has also been noted in preeclamptic human placentas, which are associated with defective STB differentiation (Chen et al. 2004, Chiang et al. 2009).

At least another mechanism by which hypoxia may inhibit STB differentiation is through the nuclear receptor, PPAR $\gamma$. We have shown that culture of mouse TSC in $2 \%$ oxygen significantly reduces PPAR $\gamma$, an upstream regulator of tri-lineage labyrinthine differentiation in the mouse placenta (including differentiation into STB) in an HIF-independent manner (Parast et al. 2009, Tache et al. 2013). Reduction of PPAR $\gamma$ has other implications for trophoblast, as this ligand-activated receptor also plays a key role in other cellular processes including metabolism and cell survival. In fact, treatment of human primary-term trophoblast with $\operatorname{PPAR} \gamma$ agonists partially rescued hypoxia (1\% oxygen)-induced injury, reducing p53 expression and apoptosis and enhancing hCG/hPL secretion (Elchalal et al. 2004). Interestingly, PPAR $\gamma$ has also been implicated in preeclampsia: rats treated with a PPAR $\gamma$ antagonist show symptoms characteristic of this syndrome, including elevated blood pressure, proteinuria, endothelial dysfunction and elevated 
placental sFlt-1, as well as decreased embryo weight (McCarthy et al. 2011a). Consistent with our data from TSC, the placentas of these mice also showed reduced labyrinthine differentiation (McCarthy et al. 2011a). Furthermore, in a rat model of reduced uterine perfusion pressure, which also led to hypertension and endothelial dysfunction, treatment with a PPAR $\gamma$ agonist alleviated some of these symptoms (McCarthy et al. 2011b). These data suggest that as a mediator of hypoxia-induced disease, PPAR $\gamma$ may in fact be a potential therapeutic target in preeclampsia.

\section{Hypoxia and EVT differentiation}

Early in gestation, within anchoring villi of the human placenta, CTBs differentiate into EVT, cells with such high migratory and invasive capacity that they have been likened to metastatic cancer cells. The bulk of the EVT differentiation takes place during the first trimester of pregnancy under low oxygen tension $\left(2-3 \% \mathrm{O}_{2}\right)$. As mentioned earlier, studies in transgenic mice have revealed a pivotal role for the HIF complex in differentiation of the junctional zone (spongiotrophoblast and TGCs), the equivalent of EVT in rodents (Adelman et al. 2000, Cowden Dahl et al. 2005). In fact, in the absence of HIF, mouse TSCs differentiate exclusively into multinucleated STB (Maltepe et al. 2005). More recently, Choi and coworkers has shown that HIF $2 \alpha$ responds to extracellular matrix-dependent signals, inducing the expression of LIMK1, which in turns rearranges both the microtubule and the actin cytoskeleton to promote TGC formation (Choi et al. 2013). A second mechanism recently identified downstream of HIF in rats and involved induction of expression of the lysine demethylase KDM3A, which in turn changed the chromatin landscape of differentiating trophoblast, promoting expression of TGC-associated genes including MMP12, which is involved in spiral artery remodeling (Chakraborty et al. 2016). In vivo evidence for the promotion of EVT differentiation and invasion under low oxygen tension comes from rats and rhesus monkeys. When pregnant rats were exposed to low oxygen (11\%) in the early post-implantation period, endovascular trophoblast invasion was enhanced, leading to a significant expansion of uterine mesometrial blood vessels (Rosario et al. 2008). In contrast, in pregnant rhesus monkeys with strictures placed around the abdominal aorta to reduce uteroplacental perfusion, interstitial trophoblast invasion was significantly increased, though endovascular trophoblast invasion remained similar to control animals (Zhou et al. 1993).
Prior to discussion of hypoxia in human EVT differentiation, some terminology regarding EVT needs to be clarified here. In much of the literature on human EVT, these cells are referred to as 'intermediate' trophoblast, or maybe even more confusingly, as СТВ. In this review, and in the rest of our published work, we refer to the trophoblast cells adjacent to the villous mesenchyme as CTB, while referring to all other trophoblasts within the cell column and invading the uterine wall, as EVT. This is based on the expression of markers: while CTBs express p63 (specifically, the $\Delta$ Np63 $\alpha$ isoform) and EGFR, EVTs have lost these markers and instead express surface HLA-G and MelCAM (Lee et al. 2007, Li et al. 2014). During this transition from CTB to EVT, the loss of p63 and gain of HLA-G are rather abrupt; however, EVTs in the proximal column remain proliferative, similar to $\mathrm{CTB}$, and gradually lose this proliferative capacity as they mature within the distal column. By the time they have reached the uterine wall, these cells become completely non-proliferative, mature EVT (Lee et al. 2007). Immature and mature EVTs are also defined by the expression of specific integrin alpha chains: as CTB transition to EVT, ITGA6 is lost, and first ITGA5 and then ITGA1 are expressed in immature and mature EVT, respectively (Damsky et al. 1994). EVTs in the uterine wall are further subdivided into interstitial and endovascular EVTs, depending on their mode of invasion.

This issue of terminology is important, as at least part of the controversy surrounding the role of hypoxia in EVT differentiation can be resolved by the correct application of the aforementioned terms. For example, multiple groups have shown that first-trimester placental explants develop 'outgrowths' when cultured in low oxygen (3\% or less), as compared to $20 \%$ oxygen (Genbacev et al. 1997, Caniggia et al. 2000). While the conclusions from these studies have been that hypoxia promotes 'СТВ proliferation', a closer look at the data reveals that actually the cell type that is being expanded is in fact positive for HLA-G (Genbacev et al. 1997) or ITGA5 (Caniggia et al. 2000), most consistent with immature EVT. The role of hypoxia in CTB self-renewal is difficult to address, as these cells rapidly lose their proliferative potential following isolation. While culture in low oxygen (2-8\%) has been shown to keep СТВ in a mononuclear state (Jiang et al. 2000, Nagamatsu et al. 2004) and, even in some cases, promotes BrdU incorporation (Genbacev et al. 1996, Nagamatsu et al. 2004), actual expansion of the СТВ population (a cell population that is positive for EGFR, ITGA6 or p63) has not been shown.

We recently evaluated the effect of oxygen tension on isolated first-trimester CTB and found that compared to 
$20 \%$ oxygen, culture in $2 \%$ oxygen led to the inhibition of syncytialization and expansion of mononuclear HLA-G+ cells (Wakeland et al. 2017). This effect was dependent on the presence of an intact HIF complex, as knockdown of HIF1 $\beta$ /ARNT abrogated this phenotype (Wakeland et al. 2017). Based on this study, we have concluded that differentiation of CTB into EVT - at least the initial transition to immature EVT-is induced under low oxygen conditions. We have also noted a similar effect of oxygen tension on hPSC-derived CTB, noting an expansion of HLA-G+ cells in an HIF-dependent manner (Horii et al. 2016); this shows that hPSCs are in fact a sound model for studying such early trophoblast differentiation events.

However, our study did not address the heterogeneity of first-trimester CTB, leaving at least two possibilities: (1) that low oxygen was causing all CTB to transition to immature EVT; (2) only a small subset of CTB was transitioning to immature EVT, and this population was expanding under our low oxygen conditions. One study recently addressed this question by identifying a subset of villous CTBs in the very early post-implantation human placenta ( 6-week gestation) that express NOTCH1 (Haider et al. 2016). They showed that in this CTB subpopulation, NOTCH1 inhibits the expression of p63, a marker of CTB 'stemness', and also represses syncytialization, thus redirecting differentiation toward the EVT lineage (Haider et al. 2016). NOTCH1 was also expressed in immature EVT of the proximal column, where it promoted proliferation and survival of immature EVT and induced genes associated with EVT 'stemness', such as MYC and VE-cadherin (Haider et al. 2016). Thus, the researchers propose these NOTCH1+ cells to be EVT progenitors within the early gestation human placenta. Interestingly, by the end of the first trimester, when oxygen tensions begin to rise, this cell population was markedly decreased; in fact, culturing primary CTB in $5 \% \mathrm{O}_{2}$ resulted in higher induction of NOTCH1 (Haider et al. 2016). These data are consistent with low oxygen levels promoting early EVT differentiation and expansion, thereby increasing the cell population needed for proper anchoring to the uterine wall and remodeling of maternal spiral arterioles.

The aforementioned data do not address the role of oxygen tension in actual invasion and vascular remodeling, the essential functions of mature EVT, which are characterized by the ITGA1 expression. The same studies that use first-trimester explants to show the expansion of immature EVT under low oxygen (2-3\%) also show a decrease in ITGA1+ cells (Genbacev et al. 1997, Caniggia et al. 2000). However, another study failed to see any difference in the ITGA1 expression within outgrowths of first-trimester explants in $8 \%$ vs $1.5 \% \mathrm{O}_{2}$ (James et al. 2006a). Yet, a fourth study compared explant culture among 20, 8 and $3 \% \mathrm{O}_{2}$, and found invasion to be reduced only under $3 \% \mathrm{O}_{2}$; nevertheless, the authors attributed this decrease in invasion to alterations in components of the urokinase plasminogen activator

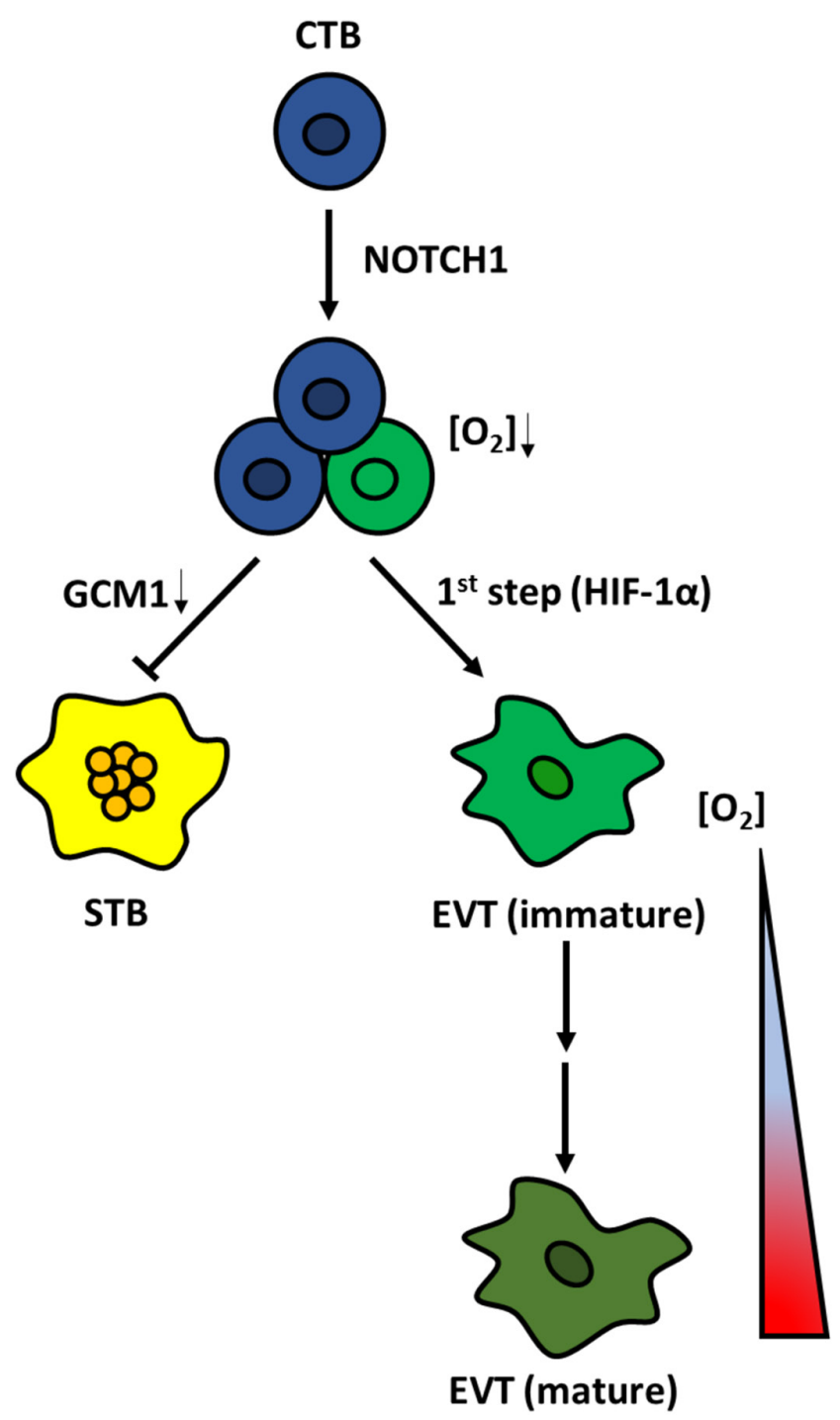

Figure 5

Schematic representation of the relationship between oxygen level and human trophoblast cell fate decisions during early placental development. NOTCH1 expression identifies an EVT progenitor cell population in early first-trimester placenta. Under low oxygen tension, the hypoxia-inducible factor (HIF) pathway is triggered and initiates EVT lineage commitment and survival of EVT progenitor cells; as oxygen tensions rise later in the first trimester, EVT progenitors mature and give rise to invasive EVTs which further invade and remodel maternal spiral arterioles. By contrast, low oxygen tension prevents STB differentiation by downregulating the expression of GCM1, a transcription factor required for cytotrophoblastic cell fusion. 
system and not to changes in cell proliferation (Lash et al. 2006). In one study of isolated first-trimester CTB, culture in $2 \% \mathrm{O}_{2}$ inhibited both ITGA1 expression and Matrigel invasion (Genbacev et al. 1996). In our own studies, with either primary (Wakeland et al. 2017) or hPSC-derived CTB (Horii et al. 2016), we have been unable to separate the two steps of EVT differentiation (i.e. by replating the immature EVT under different oxygen conditions). Thus, at this point, with all the currently available data, we propose a model, whereby low oxygen promotes immature EVT formation, while further maturation into EVT with invasive potential occurs under conditions of rising oxygen tension (Fig. 5).

It is important to mention several variables, which likely contributed to the different conclusions in the aforementioned explant studies. First, there is much variability, both within and between placenta samples; thus, both a large number of placentas and (in the cases of explant-based studies) a large number of explants from each of those placentas are necessary for these experiments (James et al. 2006b). Also, there is significant variability within explants from different weeks in the first trimester, as the placenta is rapidly growing during this period. In one elegant study, using large numbers of explants per placenta, James ad coworkers showed that the proportion of explants that produce an outgrowth decreases between 8 and 12 weeks of gestational age, regardless of oxygen tension (James et al. 2006a). Finally, another variable in these studies is culture medium, particularly the use of serum-containing vs serum-free media. Collectively, the variability among the exact gestational age, sample number and culture media, superimposed on the lack of consensus on the oxygen tensions, which should be assessed/compared, makes it difficult to properly evaluate the role of oxygen tension in EVT maturation and invasion. Future studies should meticulously address these variables.

Finally, many other questions remain with regard to oxygen tension and EVT differentiation. In particular, human EVTs are likely to be at least as heterogeneous as their counterparts (TGCs) in mice (Simmons et al. 2007). As this heterogeneity is addressed, it should be kept in mind that the response to hypoxia, and/or the mechanism of response to hypoxia, may be just as heterogeneous in the different EVT subtypes. In addition, more studies are needed to evaluate non-HIF-mediated pathways involved in EVT differentiation downstream of hypoxia. Our own study, using global gene expression profiling, identified UPR and mTORC1, along with other pathways, to be induced during the transition from CTB to immature EVT
(Wakeland et al. 2017); studies are now needed to further dissect the role of individual genes within these pathways in EVT differentiation. Finally, it is possible that different types and stages of invasion are regulated differently by oxygen tension. Additional in vitro model systems, including 3D models that incorporate all the different cells types found at the early implantation site (decidua, myometrium and immune cells such as NK cells and regulatory $\mathrm{T}$ cells), are needed to more precisely address these questions, particularly for studies addressing human pregnancy.

\section{Declaration of interest}

The authors declare that there is no conflict of interest that could be perceived as prejudicing the impartiality of this review.

\section{Funding}

This work was supported by the California Institute for Regenerative Medicine (CIRM) Physician-Scientist Award RN3-06396 (M M P) and $\mathrm{NIH} /$ National Institute of Child Health and Human Development grant R01-HD071100 (M M P). A K W was supported by the UC San Diego Respiratory Biology Training grant (T32-HL098062).

\section{Author contribution statement}

C W C wrote the first draft of this manuscript and contributed Figs 2, 3, and 5. A K W performed the experiments for, and created Fig. 4 of the manuscript, as well as reviewed the final draft. M M P contributed Fig. 1 and edited the manuscript to produce the final draft.

\section{References}

Adelman DM, Gertsenstein M, Nagy A, Simon MC \& Maltepe E 2000 Placental cell fates are regulated in vivo by HIF-mediated hypoxia responses. Genes and Development 14 3191-3203. (https://doi. org/10.1101/gad.853700)

Alsat E, Wyplosz P, Malassiné A, Guibourdenche J, Porquet D, Nessmann C \& Evain-Brion D 1996 Hypoxia impairs cell fusion and differentiation process in human cytotrophoblast, in vitro. Journal of Cellular Physiology 168 346-353. (https://doi.org/10.1002/(SICI)10974652(199608)168:2<346::AID-JCP13>3.0.CO;2-1)

Arsham AM, Howell JJ \& Simon MC 2003 A novel hypoxia-inducible factor-independent hypoxic response regulating mammalian target of rapamycin and its targets. Journal of Biological Chemistry 278 29655-29660. (https://doi.org/10.1074/jbc.M212770200)

Baczyk D, Dunk C, Huppertz B, Maxwell C, Reister F, Giannoulias D \& Kingdom JC 2006 Bi-potential behaviour of cytotrophoblasts in first trimester chorionic villi. Placenta 27 367-374. (https://doi. org/10.1016/j.placenta.2005.03.006)

Baczyk D, Drewlo S, Proctor L, Dunk C, Lye S \& Kingdom J 2009 Glial cell missing-1 transcription factor is required for the differentiation of the human trophoblast. Cell Death Differentiation 16 719-727. (https://doi.org/10.1038/cdd.2009.1)

Bilban M, Haslinger P, Prast J, Klinglmüller F, Woelfel T, Haider S, Sachs A, Otterbein LE, Desoye G \& Hiden U, et al. 2009 Identification of 
novel trophoblast invasion-related genes: heme oxygenase-1 controls motility via peroxisome proliferator-activated receptor gamma. Endocrinology 150 1000-1013. (https://doi.org/10.1210/en.2008-0456)

Bilban M, Tauber S, Haslinger P, Pollheimer J, Saleh L, Pehamberger H, Wagner O \& Knöfler M 2010 Trophoblast invasion: assessment of cellular models using gene expression signatures. Placenta $\mathbf{3 1}$ 989-996. (https://doi.org/10.1016/j.placenta.2010.08.011)

Blakeley P, Fogarty NM, del Valle I, Wamaitha SE, Hu TX, Elder K, Snell P, Christie L, Robson P \& Niakan KK 2015 Defining the three cell lineages of the human blastocyst by single-cell RNA-seq. Development 142 3151-3165. (https://doi.org/10.1242/dev.123547)

Brosens IA, Robertson WB \& Dixon HG 1972 The role of the spiral arteries in the pathogenesis of preeclampsia. Obstetric Gynecologic Annual 1 177-191.

Burton GJ \& Jauniaux E 2004 Placental oxidative stress: from miscarriage to preeclampsia. Journal of the Society for Gynecologic Investigation 11 342-352. (https://doi.org/10.1016/j.jsgi.2004.03.003)

Burton GJ \& Jauniaux E 2015 What is the placenta? American Journal of Obstetrics and Gynecology 213 S6-S8. (https://doi.org/10.1016/j. ajog.2015.07.050)

Burton GJ \& Yung HW 2011 Endoplasmic reticulum stress in the pathogenesis of early-onset pre-eclampsia. Pregnancy Hypertension 1 72-78. (https://doi.org/10.1016/j.preghy.2010.12.002)

Burton GJ, Jauniaux E \& Watson AL 1999 Maternal arterial connections to the placental intervillous space during the first trimester of human pregnancy: the Boyd collection revisited. American Journal of Obstetrics and Gynecology 181 718-724. (https://doi.org/10.1016/S00029378(99)70518-1)

Burton GJ, Woods AW, Jauniaux E \& Kingdom JC 2009 Rheological and physiological consequences of conversion of the maternal spiral arteries for uteroplacental blood flow during human pregnancy. Placenta 30 473-482. (https://doi.org/10.1016/j. placenta.2009.02.009)

Busch S, Renaud SJ, Schleussner E, Graham CH \& Markert UR 2009 mTOR mediates human trophoblast invasion through regulation of matrixremodeling enzymes and is associated with serine phosphorylation of STAT3. Experimental Cell Research 315 1724-1733. (https://doi. org/10.1016/j.yexcr.2009.01.026)

Caniggia I, Mostachfi H, Winter J, Gassmann M, Lye SJ, Kuliszewski M \& Post M 2000 Hypoxia-inducible factor-1 mediates the biological effects of oxygen on human trophoblast differentiation through TGFbeta(3). Journal of Clinical Investigation 105 577-587. (https://doi. org/10.1172/JCI8316)

Chakraborty D, Cui W, Rosario GX, Scott RL, Dhakal P, Renaud SJ, Tachibana M, Rumi MA, Mason CW, Krieg AJ, et al. 2016 HIF-KDM3AMMP12 regulatory circuit ensures trophoblast plasticity and placental adaptations to hypoxia. PNAS 113 E7212-E7221. (https://doi. org/10.1073/pnas.1612626113)

Chang CW \& Parast MM 2017 Human trophoblast stem cells: real or not real? Placenta [epub]. (https://doi.org/10.1016/j.placenta.2017.01.003)

Chen CP, Chen CY, Yang YC, Su TH \& Chen H 2004 Decreased placental GCM1 (glial cells missing) gene expression in pre-eclampsia. Placenta 25 413-421. (https://doi.org/10.1016/j.placenta.2003.10.014)

Chen L, Endler A \& Shibasaki F 2009 Hypoxia and angiogenesis: regulation of hypoxia-inducible factors via novel binding factors. Experimental and Molecular Medicine 41 849-857. (https://doi. org/10.3858/emm.2009.41.12.103)

Chiang MH, Liang FY, Chen CP, Chang CW, Cheong ML, Wang LJ, Liang CY, Lin FY, Chou CC \& Chen H 2009 Mechanism of hypoxiainduced GCM1 degradation: implications for the pathogenesis of preeclampsia. Journal of Biological Chemistry 284 17411-17419. (https://doi.org/10.1074/jbc.M109.016170)

Choi HJ, Sanders TA, Tormos KV, Ameri K, Tsai JD, Park AM, Gonzalez J, Rajah AM, Liu X, Quinonez DM, et al. 2013 ECM-dependent HIF induction directs trophoblast stem cell fate via LIMK1-mediated cytoskeletal rearrangement. PLOS ONE 8 e56949. (https://doi. org/10.1371/journal.pone.0056949)

Cowden Dahl KD, Fryer BH, Mack FA, Compernolle V, Maltepe E, Adelman DM, Carmeliet P \& Simon MC 2005 Hypoxia-inducible factors 1alpha and 2alpha regulate trophoblast differentiation. Molecular and Cellular Biology 25 10479-10491. (https://doi. org/10.1128/MCB.25.23.10479-10491.2005)

Damsky CH, Librach C, Lim KH, Fitzgerald ML, McMaster MT, Janatpour M, Zhou Y, Logan SK \& Fisher SJ 1994 Integrin switching regulates normal trophoblast invasion. Development 120 3657-3666.

Das P, Ezashi T, Schulz LC, Westfall SD, Livingston KA \& Roberts RM 2007 Effects of FGF2 and oxygen in the BMP4-driven differentiation of trophoblast from human embryonic stem cells. Stem Cell Research $\mathbf{1}$ 61-74. (https://doi.org/10.1016/j.scr.2007.09.004)

Elchalal U, Humphrey RG, Smith SD, Hu C, Sadovsky Y \& Nelson DM 2004 Troglitazone attenuates hypoxia-induced injury in cultured term human trophoblasts. American Journal of Obstetrics and Gynecology 191 2154-2159. (https://doi.org/10.1016/j.ajog.2004.05.009)

Fisher SJ 2015 Why is placentation abnormal in preeclampsia? American Journal of Obstetrics and Gynecology 213 S115-S122. (https://doi. org/10.1016/j.ajog.2015.08.042)

Fischer B \& Bavister BD 1993 Oxygen tension in the oviduct and uterus of rhesus monkeys, hamsters and rabbits. Journal of Reproduction and Fertility 99 673-679. (https://doi.org/10.1530/jrf.0.0990673)

Gangloff YC, Mueller M, Dann SG, Svoboda P, Sticker M, Spetz JF, Um SH, Brown EJ, Cereghini S, Thomas G, et al. 2004 Disruption of the mouse mTOR gene leads to early postimplantation lethality and prohibits embryonic stem cell development. Molecular and Cellular Biology 24 9508-9516. (https://doi.org/10.1128/MCB.24.21.9508-9516.2004)

Genbacev O, Joslin R, Damsky CH, Polliotti BM \& Fisher SJ 1996 Hypoxia alters early gestation human cytotrophoblast differentiation/invasion in vitro and models the placental defects that occur in preeclampsia. Journal of Clinical Investigation 97 540-550. (https://doi.org/10.1172/ JCI118447)

Genbacev O, Zhou Y, Ludlow JW \& Fisher SJ 1997 Regulation of human placental development by oxygen tension. Science 277 1669-1672. (https://doi.org/10.1126/science.277.5332.1669)

Guertin DA, Stevens DM, Thoreen CC, Burds AA, Kalaany NY, Moffat J, Brown M, Fitzgerald KJ \& Sabatini DM 2006 Ablation in mice of the mTORC components raptor, rictor, or mLST8 reveals that mTORC2 is required for signaling to Akt-FOXO and PKCalpha, but not S6K1. Developmental Cell 11 859-71. (https://doi.org/10.1016/j. devcel.2006.10.007)

Guzel E, Arlier S, Guzeloglu-Kayisli O, Tabak MS, Ekiz T, Semerci N, Larsen K, Schatz F, Lockwood CJ \& Kayisli UA 2017 Endoplasmic reticulum stress and homeostasis in reproductive physiology and pathology. International Journal of Molecular Sciences 18 pii: E792.

Haider S, Meinhardt G, Saleh L, Fiala C, Pollheimer J \& Knöfler M 2016 Notch1 controls development of the extravillous trophoblast lineage in the human placenta. PNAS 113 E7710-E7719. (https://doi. org/10.1073/pnas.1612335113)

Highet AR, Khoda SM, Buckberry S, Leemaqz S, Bianco-Miotto T, Harrington E, Ricciardelli C \& Roberts CT 2015 Hypoxia induced HIF-1/HIF-2 activity alters trophoblast transcriptional regulation and promotes invasion. European Journal of Cell Biology 94 589-602. (https://doi.org/10.1016/j.ejcb.2015.10.004)

Horii M, Li Y, Wakeland AK, Pizzo DP, Nelson KK, Sabatini K, Laurent LC, Liu Y \& Parast MM 2016 Human pluripotent stem cells as a model of trophoblast differentiation in both normal development and disease. PNAS 113 E3882-E3891. (https://doi.org/10.1073/pnas.1604747113)

Howell JJ \& Manning BD 2011 mTOR couples cellular nutrient sensing to organismal metabolic homeostasis. Trends in Endocrinology and Metabolism 22 94-102. (https://doi.org/10.1016/j.tem.2010.12.003)

Hudson CC, Liu M, Chiang GG, Otterness DM, Loomis DC, Kaper F, Giaccia AJ \& Abraham RT 2002 Regulation of hypoxia-inducible 
factor 1alpha expression and function by the mammalian target of rapamycin. Molecular and Cellular Biology 22 7004-7014.

Iwawaki T, Akai R, Yamanaka S \& Kohno K 2009 Function of IRE1 in the placenta is essential for placental development and embryonic viability. PNAS 106 16657-16662. (https://doi.org/10.1073/ pnas.0903775106)

Jaakkola P, Mole DR, Tian YM, Wilson MI, Gielbert J, Gaskell SJ, von Kriegsheim A, Hebestreit HF, Mukherji M, Schofield CJ, et al. 2001 Targeting of HIF-alpha to the von Hippel-Lindau ubiquitylation complex by O2-regulated prolyl hydroxylation. Science 292 468-472. (https://doi.org/10.1126/science.1059796)

James JL, Stone PR \& Chamley LW $2006 a$ The effects of oxygen concentration and gestational age on extravillous trophoblast outgrowth in a human first trimester villous explant model. Human Reproduction 21 2699-2705. (https://doi.org/10.1093/humrep/del212)

James JL, Stone PR \& Chamley LW 2006b The regulation of trophoblast differentiation by oxygen in the first trimester of pregnancy. Human Reproduction Update 12 137-144. (https://doi.org/10.1093/humupd/ dmi043)

James JL, Carter AM \& Chamley LW 2012 Human placentation from nidation to 5 weeks of gestation. Part I: what do we know about formative placental development following implantation? Placenta 33 327-334. (https://doi.org/10.1016/j.placenta.2012.01.020)

Jansson T, Aye IL \& Goberdhan DC 2012 The emerging role of mTORC1 signaling in placental nutrient-sensing. Placenta 33 (Supplement 2) e23-e29. (https://doi.org/10.1016/j.placenta.2012.05.010)

Jauniaux E, Ramsay B \& Campbell S 1994 Ultrasonographic investigation of placental morphologic characteristics and size during the second trimester of pregnancy. American Journal of Obstetrics and Gynecology 170 130-137. (https://doi.org/10.1016/S0002-9378(13)70293-X)

Jauniaux E, Watson AL, Hempstock J, Bao YP, Skepper JN \& Burton GJ 2000 Onset of maternal arterial blood flow and placental oxidative stress. A possible factor in human early pregnancy failure. American Journal of Pathology 157 2111-2122. (https://doi.org/10.1016/S00029440(10)64849-3)

Jewell UR, Kvietikova I, Scheid A, Bauer C, Wenger RH \& Gassmann M 2001 Induction of HIF-1alpha in response to hypoxia is instantaneous. FASEB Journal 15 1312-1314.

Jiang B, Kamat A \& Mendelson CR 2000 Hypoxia prevents induction of aro- matase expression in human trophoblast cells in culture: potential inhibitory role of the hypoxia-inducible transcription factor Mash-2 (mammalian acha- ete-schute homologous protein-2). Molecular Endocrinology 14 1661-1673. (https://doi.org/10.1210/ mend.14.10.0539)

John R \& Hemberger M 2012 A placenta for life. Reproductive BioMedicine Online 25 5-11. (https://doi.org/10.1016/j.rbmo.2012.03.018)

Julian CG 2011 High altitude during pregnancy. Clinics in Chest Medicine 32 21-31. (https://doi.org/10.1016/j.ccm.2010.10.008)

Kingdom JC \& Kaufmann P 1997 Oxygen and placental villous development: origins of fetal hypoxia. Placenta 18 613-621. (https://doi.org/10.1016/S0143-4004(97)90000-X)

Krampl ER, Espinoza-Dorado J, Lees CC, Moscoso G, Bland JM \& Campbell S 2001 Maternal uterine artery Doppler studies at high altitude and sea level. Ultrasound in Obstetrics and Gynecology 18 578-582. (https://doi.org/10.1046/j.0960-7692.2001.00579.x)

Lando D, Peet DJ, Gorman JJ, Whelan DA, Whitelaw ML \& Bruick RK $2002 \mathrm{FIH}-1$ is an asparaginyl hydroxylase enzyme that regulates the transcriptional activity of hypoxia-inducible factor. Genes \& Development 16 1466-1471. (https://doi.org/10.1101/gad.991402)

Lash GE, Otun HA, Innes BA, Bulmer JN, Searle RF \& Robson SC 2006 Low oxygen concentrations inhibit trophoblast cell invasion from early gestation placental explants via alterations in levels of the urokinase plasminogen activator system. Biology of Reproduction $\mathbf{7 4}$ 403-409. (https://doi.org/10.1095/biolreprod.105.047332)

Lee JW, Bae SH, Jeong JW, Kim SH \& Kim KW 2004 Hypoxia-inducible factor (HIF-1)alpha: its protein stability and biological functions.
Experimental and Molecular Medicine 36 1-12. (https://doi.org/10.1038/ emm.2004.1)

Lee Y, Kim KR, McKeon F, Yang A, Boyd TK, Crum CP \& Parast MM 2007 A unifying concept of trophoblastic differentiation and malignancy defined by biomarker expression. Human Pathology 38 1003-1013. (https://doi.org/10.1016/j.humpath.2006.12.012)

Li Y \& Parast MM 2014 BMP4 regulation of human trophoblast development. International Journal of Developmental Biology $\mathbf{5 8}$ 239-246. (https://doi.org/10.1387/ijdb.130341mp)

Li Y, Moretto-Zita M, Soncin F, Wakeland A, Wolfe L, Leon-Garcia S, Pandian R, Pizzo D, Cui L, Nazor K, et al. 2013 BMP4-directed trophoblast differentiation of human embryonic stem cells is mediated through a $\Delta \mathrm{Np}^{2} 3^{+}$cytotrophoblast stem cell state. Development 140 3965-76. (https://doi.org/10.1242/dev.092155)

Li Y, Moretto-Zita M, Leon-Garcia S \& Parast MM 2014 p63 inhibits extravillous trophoblast migration and maintains cells in a cytotrophoblast stem cell-like state. American Journal of Pathology 184 3332-43. (https://doi.org/10.1016/j.ajpath.2014.08.006)

Malassine A \& Cronier L 2002 Hormones and human trophoblast differentiation: a review. Endocrine 19 3-11. (https://doi.org/10.1385/ ENDO:19:1:3)

Maltepe E, Krampitz GW, Okazaki KM, Red-Horse K, Mak W, Simon MC \& Fisher SJ 2005 Hypoxia-inducible factor-dependent histone deacetylase activity determines stem cell fate in the placenta. Development 132 3393-3403. (https://doi.org/10.1242/dev.01923)

Maynard MA, Qi H, Chung J, Lee EH, Kondo Y, Hara S, Conaway RC, Conaway JW \& Ohh M 2003 Multiple splice variants of the human HIF-3 alpha locus are targets of the von Hippel-Lindau E3 ubiquitin ligase complex. Journal of Biological Chemistry 278 11032-11040. (https://doi.org/10.1074/jbc.M208681200)

McCarthy FP, Drewlo S, English FA, Kingdom J, Johns EJ, Kenny LC \& Walsh SK 2011a Evidence implicating peroxisome proliferator-activated receptor- $\gamma$ in the pathogenesis of preeclampsia. Hypertension 58 882-887. (https://doi.org/10.1161/ HYPERTENSIONAHA.111.179440)

McCarthy FP, Drewlo S, Kingdom J, Johns EJ, Walsh SK \& Kenny LC $2011 b$ Peroxisome proliferator-activated receptor- $\gamma$ as a potential therapeutic target in the treatment of preeclampsia. Hypertension $\mathbf{5 8}$ 280-286. (https://doi.org/10.1161/HYPERTENSIONAHA.111.172627)

Murakami M, Ichisaka T, Maeda M, Oshiro N, Hara K, Edenhofer F, Kiyama H, Yonezawa K \& Yamanaka S 2004 mTOR is essential for growth and proliferation in early mouse embryos and embryonic stem cells. Molecular and Cellular Biology 24 6710-6718. (https://doi. org/10.1128/MCB.24.15.6710-6718.2004)

Nagamatsu T, Fujii T, Yamashita T, Miki A, Kanai T, Kusumi M, Osuga Y, Kosuma S \& Taketani Y 2004 Hypoxia does not reduce HLAG expression on extravillous cytotrophoblast. Journal of Reproductive Immunology 63 85-95. (https://doi.org/10.1016/j.jri.2004.07.001)

Nevo O, Soleymanlou N, Wu Y, Xu J, Kingdom J, Many A, Zamudio S \& Caniggia I 2006 Increased expression of sFlt-1 in in vivo and in vitro models of human placental hypoxia is mediated by HIF-1. American Journal of Physiology: Regulatory, Integrative and Comparative Physiology 291 R1085-R1093. (https://doi.org/10.1152/ajpregu.00794.2005)

Parast MM, Yu H, Ciric A, Salata MW, Davis V \& Milstone DS 2009 PPARgamma regulates trophoblast proliferation and promotes labyrinthine trilineage differentiation. PLOS ONE 4 e8055. (https://doi.org/10.1371/journal.pone.0008055)

Patel J, Landers K, Mortimer RH \& Richard K 2010 Regulation of hypoxia inducible factors (HIF) in hypoxia and normoxia during placental development. Placenta 31 951-957. (https://doi.org/10.1016/j. placenta.2010.08.008)

Poston L Raijmakers MT 2004 Trophoblast oxidative stress, antioxidants and pregnancy outcome--a review. Placenta 25 (Suppl A) S72-S78.

Proud CG 2007 Signaling to translation: how signal transduction pathways control the protein synthetic machinery. Biochemical Journal 403 217-234. (https://doi.org/10.1042/BJ20070024) http://joe.endocrinology-journals.org

https://doi.org/10.1530/JOE-17-0402 (c) 2018 Society for Endocrinology Published by Bioscientifica Ltd. Printed in Great Britain 
Rajakumar A, Brandon HM, Daftary A, Ness R \& Conrad KP 2004 Evidence for the functional activity of hypoxia-inducible transcription factors overexpressed in preeclamptic placentae. Placenta 25 763-769. (https://doi.org/10.1016/j.placenta.2004.02.011)

Roberts RM, Loh KM, Amita M, Bernardo AS, Adachi K, Alexenko AP, Schust DJ, Schulz LC, Telugu BP, Ezashi T, et al. 2014 Differentiation of trophoblast cells from human embryonic stem cells: to be or not to be? Reproduction 147 D1-D12. (https://doi.org/10.1530/REP-14-0080)

Rodesch F, Simon P, Donner C \& Jauniaux E 1992 Oxygen measurements in endometrial and trophoblastic tissues during early pregnancy. Obstetrics and Gynecology 80 283-285.

Roos S, Jansson N, Palmberg I, Säljö K, Powell TL \& Jansson T 2007 Mammalian target of rapamycin in the human placenta regulates leucine transport and is down-regulated in restricted fetal growth. Journal of Physiology 582 449-459. (https://doi.org/10.1113/ jphysiol.2007.129676)

Rosario GX, Konno T \& Soares MJ 2008 Maternal hypoxia activates endovascular trophoblast cell invasion. Developmental Biology $\mathbf{3 1 4}$ 362-375. (https://doi.org/10.1016/j.ydbio.2007.12.007)

Shahbazi MN, Jedrusik A, Vuoristo S, Recher G, Hupalowska A, Bolton V, Fogarty NM, Campbell A, Devito LG \& Ilic D, et al. 2016 Selforganization of the human embryo in the absence of maternal tissues. Nature Cell Biology 18 700-708. (https://doi.org/10.1038/ncb3347)

Simmons DG, Fortier AL \& Cross JC 2007 Diverse subtypes and developmental origins of trophoblast giant cells in the mouse placenta. Developmental Biology 304 567-78. (https://doi. org/10.1016/j.ydbio.2007.01.009)

Simon MC \& Keith B 2008 The role of oxygen availability in embryonic development and stem cell function. Nature Reviews Molecular and Cellular Biology 9 285-296. (https://doi.org/10.1038/nrm2354)

Soares MJ, Chakraborty D, Karim Rumi MA, Konno T \& Renaud SJ 2012 Rat placentation: an experimental model for investigating the hemochorial maternal-fetal interface. Placenta 33 233-243. (https://doi.org/10.1016/j.placenta.2011.11.026)

Soncin F, Natale D \& Parast MM 2015 Signaling pathways in mouse and human trophoblast differentiation: a comparative review. Cellular and Molecular Life Sciences 72 1291-1302. (https://doi.org/10.1007/s00018014-1794-x)

Tache V, Ciric A, Moretto-Zita M, Li Y, Peng J, Maltepe E, Milstone DS \& Parast MM 2013 Hypoxia and trophoblast differentiation: a key role for PPAR $\gamma$. Stem Cells and Development 22 2815-2824. (https://doi. org/10.1089/scd.2012.0596)

Tal R 2012 The role of hypoxia and hypoxia-inducible factor-1alpha in preeclampsia pathogenesis. Biology of Reproduction $\mathbf{8 7} 134$ (https://doi.org/10.1093/biolreprod/87.s1.134)

Tal R, Shaish A, Barshack I, Polak-Charcon S, Afek A, Volkov A, Feldman B, Avivi C \& Harats D 2010 Effects of hypoxia-inducible factor-1alpha overexpression in pregnant mice: possible implications for preeclampsia and intrauterine growth restriction. American
Journal of Pathology 177 2950-2962. (https://doi.org/10.2353/ ajpath.2010.090800)

Tanaka S, Kunath T, Hadjantonakis AK, Nagy A \& Rossant J 1998 Promotion of trophoblast stem cell proliferation by FGF4. Science 282 2072-2075. (https://doi.org/10.1126/science.282.5396.2072)

Tuuli MG, Longtine MS \& Nelson DM 2011 Review: oxygen and trophoblast biology-A source of controversy. Placenta 32(Supplement 2) S109-S118. (https://doi.org/10.1016/j.placenta.2010.12.013)

Wakeland AK, Soncin F, Moretto-Zita M, Chang CW, Horii M, Pizzo D, Nelson KK, Laurent LC \& Parast MM 2017 Hypoxia directs human extravillous trophoblast differentiation in a hypoxia-inducible factor-dependent manner. American Journal of Pathology 187 767-780. (https://doi.org/10.1016/j.ajpath.2016.11.018)

Wich C, Kausler S, Dotsch J, Rascher W \& Knerr I 2009 Syncytin-1 and glial cells missing a: hypoxia-induced deregulated gene expression along with disordered cell fusion in primary term human trophoblasts. Gynecologic and Obstetric Investigation 68 9-18. (https://doi.org/10.1159/000209396)

Wouters BG, van den Beucken T, Magagnin MG, Koritzinsky M, Fels D $\&$ Koumenis C 2005 Control of the hypoxic response through regulation of mRNA translation. Seminars in Cell and Developmental Biology 16 487-501. (https://doi.org/10.1016/j.semcdb.2005.03.009)

Yang Y, Arenas-Hernandez M, Gomez-Lopez N, Dai J, Parker GC, Puscheck EE \& Rappolee DA 2016 Hypoxic stress forces irreversible differentiation of a majority of mouse trophoblast stem cells despite FGF4. Biology of Reproduction 95 110. (https://doi.org/10.1095/ biolreprod.116.138412)

Yinon Y, Nevo O, Xu J, Many A, Rolfo A, Todros T, Post M \& Caniggia I 2008 Severe intrauterine growth restriction pregnancies have increased placental endoglin levels: hypoxic regulation via transforming growth factor-beta 3. American Journal of Pathology 172 77-85. (https://doi.org/10.2353/ajpath.2008.070640)

Yung HW, Calabrese S, Hynx D, Hemmings BA, Cetin I, CharnockJones DS \& Burton GJ 2008 Evidence of placental translation inhibition and endoplasmic reticulum stress in the etiology of human intrauterine growth restriction. American Journal of Pathology 173 451-462. (https://doi.org/10.2353/ajpath.2008.071193)

Yung HW, Hemberger M, Watson ED, Senner CE, Jones CP, Kaufman RJ Charnock-Jones DS \& Burton GJ 2012 Endoplasmic reticulum stress disrupts placental morphogenesis: implications for human intrauterine growth restriction. Journal of Pathology 228 554-564. (https://doi.org/10.1002/path.4068)

Zamudio S 2003 The placenta at high altitude. High Altitude Medicine and Biology 4 171-191. (https://doi.org/10.1089/152702903322022785)

Zhou Y, Chiu K, Brescia RJ, Combs CA, Katz MA, Kitzmiller JL, Heilbron DC \& Fisher SJ 1993 Increased depth of trophoblast invasion after chronic constriction of the lower aorta in rhesus monkeys. American Journal of Obstetrics and Gynecology 169 224-229. (https://doi.org/10.1016/0002-9378(93)90172-F)

Received in final form 4 September 2017

Accepted 12 September 2017 